\title{
Short communication: Prevalence of digital dermatitis in Canadian dairy cattle classified as high, average, or low antibody- and cell-mediated immune responders
}

\author{
S. L. Cartwright, ${ }^{* 1}$ F. Malchiodi, $†$ K. Thompson-Crispi,‡ F. Miglior, $† \S$ and B. A. Mallard ${ }^{*} \dagger$ \\ *Department of Pathobiology, and \\ tCenter of Genetic Improvement of Livestock, University of Guelph, Guelph, ON, Canada N1G 2W1 \\ ¥Trouw Nutrition Agresearch, Nutreco Canada Inc., Guelph, ON, Canada N1G 4T2 \\ §Canadian Dairy Network, Guelph, ON, Canada N1K 1E5
}

\section{ABSTRACT}

Lameness is a major animal welfare issue affecting Canadian dairy producers, and it can lead to production, reproduction, and health problems in dairy cattle herds. Although several different lesions affect dairy cattle hooves, studies show that digital dermatitis is the most common lesion identified in Canadian dairy herds. It has also been shown that dairy cattle classified as having high immune response (IR) have lower incidence of disease compared with those animals with average and low IR; therefore, it has been hypothesized that IR plays a role in preventing infectious hoof lesions. The objective of this study was to compare the prevalence of digital dermatitis in Canadian dairy cattle that were classified for antibody-mediated (AMIR) and cell-mediated (CMIR) immune response. Cattle $(\mathrm{n}=329)$ from 5 commercial dairy farms in Ontario were evaluated for IR using a patented test protocol that captures both AMIR and CMIR. Individuals were classified as high, average, or low responders based on standardized residuals for AMIR and CMIR. Residuals were calculated using a general linear model that included the effects of herd, parity, stage of lactation, and stage of pregnancy. Hoof health data were collected from 2011 to 2013 by the farm's hoof trimmer using Hoof Supervisor software (KS Dairy Consulting Inc., Dresser, WI). All trim events were included for each animal, and lesions were assessed as a binary trait at each trim event. Hoof health data were analyzed using a mixed model that included the effects of herd, stage of lactation (at trim date), parity (at trim date), IR category (high, average, and low), and the random effect of animal. All data were presented as prevalence within IR category. Results showed that cows with

\footnotetext{
Received October 14, 2016.

Accepted June 12, 2017.

${ }^{1}$ Corresponding author: cartwris@uoguelph.ca
}

high AMIR had significantly lower prevalence of digital dermatitis than cattle with average and low AMIR. No significant difference in prevalence of digital dermatitis was observed between high, average, and low CMIR cows. These results indicate that having more robust AMIR is associated with lower prevalence of digital dermatitis hoof lesions.

Key words: digital dermatitis, immune response, dairy cattle

\section{Short Communication}

Lameness is one of the most costly and serious animal welfare issues affecting the Canadian dairy industry today (O'Callaghan et al., 2003; Solano et al., 2015). The reason for this is that lameness has been associated with many issues, including reduced milk yield (Amory et al., 2008) and lower fertility (Hernandez et al., 2001; Buch et al., 2011), likely due to the fact that cattle are experiencing pain and discomfort and thus spending more time lying down and less time eating (Espejo et al., 2006). Studies have estimated the prevalence of lameness in Canadian dairy cattle to range between 20 and $35 \%$, with the most common lesion being digital dermatitis at an incidence rate of $15 \%$ of all recorded lesions (Solano et al., 2016). Digital dermatitis is an infectious hoof lesion that typically affects the skin at the base of the hoof heel. It is highly contagious and is caused by bacterial pathogens that thrive in damp and dirty conditions (Clegg et al., 2016), making it difficult to prevent the occurrence of these lesions. Efforts have been made through foot bathing and treating the lesions with antibiotics during trimming; however, the prevalence of digital dermatitis continues to remain high.

Several studies have been done in different species showing that animals with a more robust or high IR have lower occurrence of disease (Covelli et al., 1989; Raymond et al., 1998; Wagter et al., 2000). Specifi- 
cally in dairy cattle, studies have shown that cattle classified as high immune responders not only have a lower incidence of mastitis but also reduced incidence of other common diseases, including metritis, ketosis, displaced abomasum, and retained fetal membrane (Thompson-Crispi et al., 2012b, 2013). This is because the immune system controls an animal's ability to respond to invading pathogens. It has been shown that the cell-mediated immune response (CMIR; also known as type 1 response) predominates in protection against intracellular pathogens (such as viruses or $M y$ cobacterium paratuberculosis), whereas the antibodymediated immune response (AMIR; known as the type 2 response depending on the antibody isotype involved) predominates in protection against extracellular pathogens such as bacteria (Wikenheiser and Stumhofer, 2016). In studies where animals have been selected or identified for high or enhanced immune response, it has been shown that these animals have a balance between type 1 and type 2 responses (Crawley et al., 2005; Heriazon et al., 2011), suggesting they would have overall broad-based resistance to disease, which is important for defense against the wide array of pathogens that exist. (Stear et al., 2001, 2016; Mallard et al., 2015). Selection for resistance against particular pathogens may also improve disease resistance (Meijerink et al., 2000). Although this holds true for the particular pathogen being selected against, it is also limiting as it generally only confers resistance to one pathogen. Certain components of the immune system can be negatively genetically correlated, indicating that selecting for resistance against one pathogen may cause susceptibility to others (Nino-Soto et al., 2008; Thompson-Crispi et al., 2012a). Therefore, because high immune responders demonstrate a greater ability to respond to a wide array of pathogens and resist several different diseases, we hypothesized that cattle classified as high immune responders are able to resist pathogens that cause infectious hoof lesions, specifically digital dermatitis. To date, the prevalence of digital dermatitis has yet to be evaluated in animals ranked based on IR, leading to the objective of this study, which was to evaluate the prevalence of digital dermatitis in Canadian dairy cattle classified as high, average, and low immune responders.

Cattle $(\mathrm{n}=329)$ from 5 different commercial dairy farms in Ontario were evaluated for immune response (IR) using a patented test protocol that was adapted from previously described protocols (Wagter et al., 2000; Hernandez et al., 2005). Briefly, blood samples were taken on d 0 from the tail vein and animals were immunized intramuscularly with known type 1 and type 2 antigens (Heriazon et al., 2013). Fourteen days later, animals were bled again from the tail vein and a delayed-type hypersensitivity test initiated in the tail folds. Triplicate measurements were taken on either side of the tail fold using Harpenden skin calipers (Creative Health Products Inc., Ann Arbor, MI) and intradermal injections of control (PBS) and type 1 antigen were given on either side of the tail folds (Hernandez et al., 2005). On d 15, final skin-fold measurements are taken in triplicate as an indicator of CMIR. The blood samples taken on d 0 and 14 were centrifuged $(700 \times$ $g$ for $15 \mathrm{~min}$ ), and serum was obtained and aliquoted for storage at $-20^{\circ} \mathrm{C}$ until time of analysis. Antibody activity to the type 2 antigen was evaluated by indirect ELISA (Heriazon et al., 2013). Briefly, 96-well plates were coated with the type 2 antigen dissolved in carbonate buffer and incubated for $24 \mathrm{~h}$ at $4^{\circ} \mathrm{C}$. The following day, plates were blocked with 3\% Tween 20 (SigmaAldrich, Oakville, ON, Canada), 1.5\% BSA (SigmaAldrich), and $1.5 \%$ fetal calf serum (Sigma-Aldrich) in PBS. Sera samples were diluted to 1:50 and 1:200 and controls diluted to 1:200 and 1:400. Positive controls were obtained by pooling d-14 sera from the top 10 cows for IgG antibody activity to the type 2 antigen, and negative controls were obtained by pooling $\mathrm{d}-0$ sera from 10 cows. All controls and test sera were added to the plate in quadruplicate. Monoclonal mouse antibovine IgG conjugated to alkaline phosphatase (SigmaAldrich) was diluted 1:8,000 in Tris buffer and added to the plate. Plates were read at wavelengths of 405 and $630 \mathrm{~nm}$, with the $630 \mathrm{~nm}$ results being subtracted from the $405 \mathrm{~nm}$ results. Plates were read until positive controls from this result reached an optical density $(\mathrm{OD}) \geq 0.999$. The positive controls were corrected back to an OD of 1 with all samples being corrected back to the positive control to compare samples across different plates and run on different days as described previously (Heriazon et al., 2013). To minimize error, if controls or samples had a coefficient of variation greater than $10 \%$, the sample or plate (in the case of controls) was repeated.

All IR data were log-transformed to normalize the distribution, and CMIR and AMIR were analyzed using a general linear model in SAS (SAS Institute Inc., Cary, NC) as follows:

$$
y_{i j k l}=\mu+d_{i}+l_{j}+p_{k}+h_{l}+e_{i j k l},
$$

where $y_{i j k l}=$ AMIR or CMIR, $\mu=$ overall mean, $d_{i}$ $=\mathrm{d} 0$ data for AMIR or control site for CMIR, $l_{j}=$ parity effect (parity $0,1,2,3$, and $\geq 4$ ), $p_{k}=$ pregnancy status effect (not pregnant, 1-100, or 101-200, >200 d in calf), $h_{l}=$ herd effect $\left(1,2,3,4\right.$, and 5), and $e_{i j k l}=$ residual error. Residuals were obtained from the model, with the PROC UNIVARIATE procedure in SAS used to test the residuals for normality. Residuals were then 
converted to standardized residuals with a mean of zero. Cattle were ranked as high or low if standardized residuals were $>1$ standard deviation (SD) above the mean or $<1 \mathrm{SD}$ below the mean response for each trait, respectively. Average AMIR and CMIR cows had standardized residuals within $1 \mathrm{SD}$ of the mean (Thompson-Crispi et al., 2013).

Hoof health data were collected by the farms' hoof trimmer, using Hoof Supervisor software (KS Dairy Consulting Inc., Dresser, WI), from December 2011 to November 2013. Five trimmers were involved in the study, with each trimmer only being involved on a single farm. All trim events were included for each animal during this period. Digital dermatitis was assessed as a binary trait at each event $(1=$ presence of digital dermatitis, $0=$ no digital dermatitis detected). To ensure that consistency of defining lesions was maintained between each hoof trimmer, all were trained by the same person and provided with visual documents created by Alberta hoof trimmers before commencing the study (Alberta Dairy Hoof Health Project, 2014). All hoof health data were analyzed using the following SAS mixed model:

$$
y_{i j k l m}=\mu+p_{i}+i_{j}+h_{k}+l_{l}+a_{m}+e_{i j k l m},
$$

where $y_{i j k l m}=$ digital dermatitis; $\mu=$ overall mean; $p_{i}=$ parity at trim date $(i=0,1,2,3$, and $\geq 4) ; i_{j}=$ immune response ranking ( $j=$ high, average and low); $h_{k}=$ herd $(1,2,3,4$, and 5$) ; l_{l}=$ stage of lactation at trim date (not lactating, 1-99 d, 100-199 d, and 200-500 d), $a_{m}$ $=$ random effect of animal, and $e_{i j k l m}=$ standard error. Significance is reported at $P<0.05$. All graphs are presented as prevalence in percentages; however, significance is based on the differences between the least squared means calculated from the model.

Overall prevalence of digital dermatitis in this study was $34 \%$. Results for the prevalence of digital dermatitis in animals ranked as high, average, and low for AMIR are presented in Figure 1. Figure 1 shows that the high (20\% of high responders infected with digital dermatitis) antibody responders had significantly lower $(P<0.05)$ prevalence of digital dermatitis compared with average $(35 \%$ of average responders infected with digital dermatitis) and low (40\% of low responders infected with digital dermatitis) antibody responders.

Figure 2 shows the results for prevalence of digital dermatitis in animals ranked as high, average, and low for CMIR. No significant difference was observed between high $(38 \%$ of high responders infected with digital dermatitis), average (33\% of average responders infected with digital dermatitis), and low (38\% of low responders infected with digital dermatitis) CMIR for prevalence of digital dermatitis.

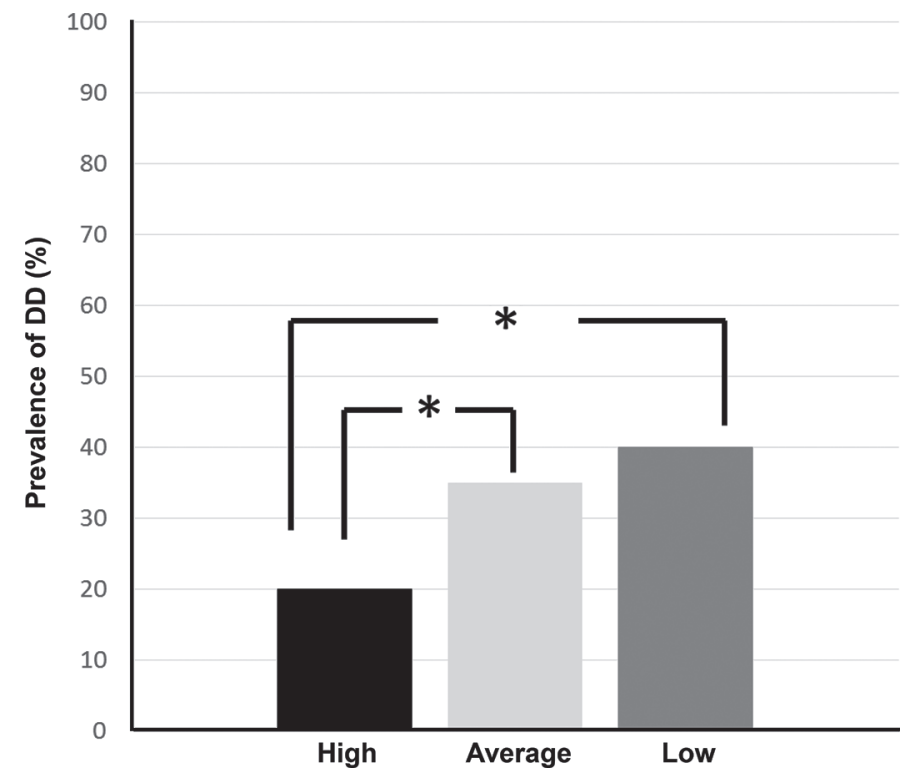

Figure 1. Prevalence of digital dermatitis (DD) in cattle ranked as high, average, and low for antibody-mediated immune response. *Significant differences reported at $P<0.05$.

This study found that cows classified as high antibody responders had significantly lower prevalence of digital dermatitis compared with average and low responders. Digital dermatitis is an infectious disease that commonly affects hooves of cattle and can be caused by multiple bacterial pathogens (Yano et al., 2010). Because antibody responses are typically associated with defense against extracellular pathogens (Estes and Brown, 2002), including bacteria, it makes sense that antibody responses would play a major role

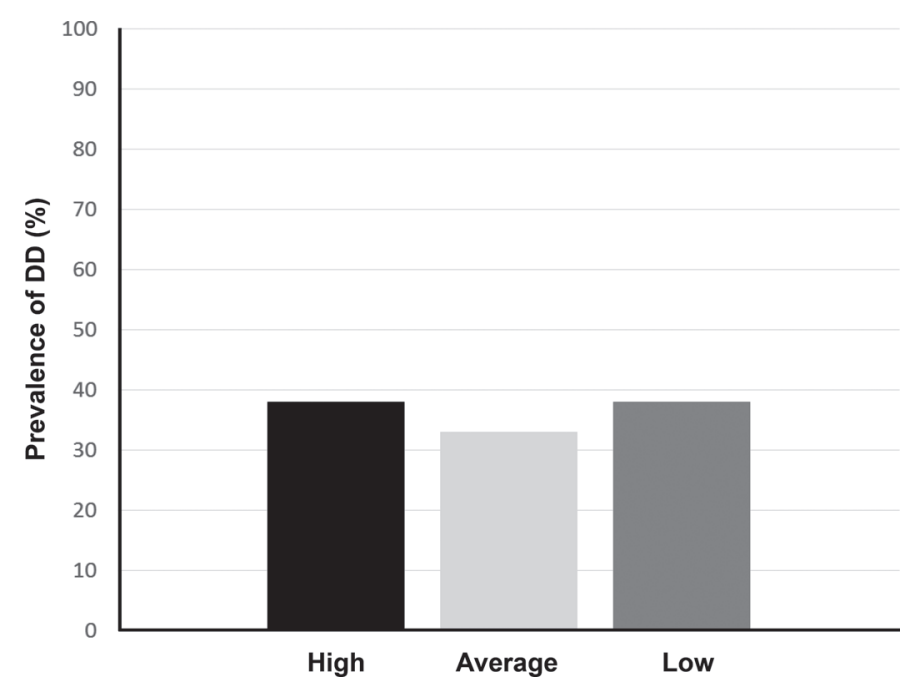

Figure 2. Prevalence of digital dermatitis (DD) in cattle ranked as high, average, and low for cell-mediated immune response. 
in defense against the bacterial pathogens that cause digital dermatitis. These results are similar to those seen in a previous study examining mastitis, which is another disease typically caused by extracellular bacterial pathogens. In the previous study, cattle classified as high antibody responders had fewer cases of mastitis compared with average and low antibody responders, and cows with low AMIR tended to have the most severe cases of mastitis (Thompson-Crispi et al., 2013).

Results also indicated that no significant difference was observed between high, average, and low CMIR cows for prevalence of digital dermatitis. Because CMIR is primarily involved in defense against intracellular pathogens (Wikenheiser and Stumhofer 2016) and it has been shown that the main pathogen involved in digital dermatitis is extracellular (Clegg et al., 2016), it makes sense that a significant difference would not be observed for CMIR cows. Previous research has shown cows classified as both high AMIR and high CMIR have lower incidence of several different diseases (Thompson-Crispi et al., 2012b). Recent studies in commercial Holsteins bred using semen from high IR sires have also indicated that these offspring have less disease than females bred to other sires (Larmer and Mallard, 2016). Also, noteworthy is the fact that the cells mainly associated with the cell-mediated immune system, such as T-helper lymphocytes, secrete cytokines that help in initiation of a protective antibody response (Alberts et al., 2002). Therefore, because AMIR and CMIR often work together to control infectious disease and no detrimental effect was observed with high CMIR cows, these results suggest that having high CMIR in conjunction with high AMIR is beneficial in reducing the prevalence of infectious hoof lesions. Collectively, these studies support the idea that animals with more robust immune responses are better able to respond to invading pathogens, including the bacteria that may result in digital dermatitis, and to clear them before disease occurs.

In conclusion, this study showed that cows classified as high AMIR had significantly reduced prevalence of digital dermatitis lesions. We observed no significant difference between high, average, and low CMIR cows, indicating no detrimental effects of a high CMIR on the prevalence of digital dermatitis. Therefore, having high IR cattle in a herd or breeding for high IR will not only potentially improve disease occurrence but may also decrease the prevalence of infectious hoof lesions, thus improving both overall welfare and economic gains.

\section{ACKNOWLEDGMENTS}

This research was funded by grants from National Sciences and Engineering (Ottawa, Ontario, Canada),
Boviteq (Saint-Hyacinthe, Québec, Canada), the Dairy Research Cluster Initiative (Dairy Farmers of Canada, Ottawa, Ontario; Agriculture and Agri-Food Canada, Guelph, Ontario; the Canadian Dairy Network, Guelph, Ontario; and the Canadian Dairy Commission, Ottawa, Ontario) and Alberta Milk (Edmonton, AB, Canada). The authors thank all the hoof trimmers for willingly providing data and for their participation in this project. The authors also thank the veterinarians who helped collect samples for immune response phenotyping.

\section{REFERENCES}

Alberta Dairy Hoof Health Project. 2014. The Alberta dairy hoof health project: Lesion severity scoring guide. http://dairyhoofhealth .info/Lesion-Severity-Guide-v0.7.pdf.

Alberts, B., A. Johnson, J. Lewis, M. Raff, K. Roberts, and P. Walter. 2002. Helper T cells and lymphocyte activation. Pages 3572-3581 in Molecular Biology of the Cell. 4th ed. Garland Science, New York, NY

Amory, J. R., Z. E. Barker, J. L. Wright, S. A. Mason, R. W. Blowey, and L. E. Green. 2008. Associations between sole ulcer, white line disease and digital dermatitis and milk yield of 1824 dairy cows on 30 dairy cow farms in England and Wales from February 2003-November 2004. Prev. Vet. Med. 83:381-391.

Buch, L. H., A. C. Sorensen, J. Lassen, P. Berg, J. A. Eriksson, J. H. Jakobsen, and M. K. Sorensen. 2011. Hygiene-related and feed-related hoof diseases show different patterns of genetic correlations to clinical mastitis and female fertility. J. Dairy Sci. 94:1540-1551.

Clegg, S. R., H. E. Crosby-Durrani, J. Bell, R. Blundell, R. W. Blowey, S. D. Carter, and N. J. Evans. 2016. Detection and isolation of digital dermatitis treponemes from bovine pressure sores. J. Comp. Pathol. 154:273-282.

Covelli, V., D. Mouton, V. Di Majo, Y. Bouthillier, C. Bangrazi, J. C. Mevel, S. Rebessi, G. Doria, and G. Biozzi. 1989. Inheritance of immune responsiveness, life span and disease incidence in interline crosses of mice selected for high or low multispecific antibody production. J. Immun. 142:1224-1234.

Crawley, A. M., B. Mallard, and B. N. Wilkie. 2005. Genetic selection for high and low immune response in pigs: Effects on immunoglobulin isotype expression. Vet. Immunol. Immunopathol. 108:71-76.

Espejo, L. A., M. I. Endres, and J. A. Salfer. 2006. Prevalence of lameness in high-producing Holstein cows housed in freestall barns in Minnesota. J. Dairy Sci. 89:3052-3058.

Estes, D. M., and W. C. Brown. 2002. Type 1 and type 2 responses in regulation of Ig isotype expression in cattle. Vet. Immunol. Immunopathol. 90:1-10.

Heriazon, A., K. Hamiton, J. Huffman, B. N. Wilkie, W. Sears, M. Quinton, and B. A. Mallard. 2011. Immunoglobulin isotypes of lactating Holstein cows classified as high, average and low type- 1 or -2 immune responders. Vet. Immunol. Immunopathol. 144:259-269.

Heriazon, A., M. Quinton, F. Miglior, K. E. Leslie, W. Sears, and B. A. Mallard. 2013. Phenotypic and genetic parameters of antibody and delayed-type hypersensitivity responses of lactating Holstein cow. Vet. Immunol. Immunopathol. 154:83-92.

Hernandez, A., J. A. Yager, B. N. Wilkie, K. E. Leslie, and B. A. Mallard. 2005. Evaluation of bovine cutaneous delayed-type hypersensitivity (DTH) to various test antigens and a mitogen using several adjuvants. Vet. Immunol. Immunopathol. 104:45-58.

Hernandez, J., J. K. Shearer, and D. W. Webb. 2001. Effect of lameness on the calving-to-conception interval in dairy cows. J. Am. Vet. Med. Assoc. 218:1611-1614.

Larmer, S., and B. A. Mallard. 2016. High immune response sires reduce disease incidence in North American large commercial dairy. British Cattle Veterinarians Assoc. Annu. Congr. 
Mallard, B. A., M. Emam, M. Paibomesai, K. Thompson-Crispi, and L. Wagter-Lesperance. 2015. Genetic selection of cattle for improved immunity and health. Jpn. J. Vet. Res. 63(Suppl. 1):S37S44.

Meijerink, E., S. Neuenschwander, R. Fries, A. Dinter, H. Bertschinger, U. Stranzinger, G. Vogeli, and P. Vogeli. 2000. A DNA Polymorphism influencing $\alpha(1,2)$ fucosyltransferase activity enzyme of the pig FUT 1 enzyme determines susceptibility of small intestinal epithelium to Escherichia coli F18 adhesion. Immunogenetics 52:129-136.

Nino-Soto, M. I., A. Heriazon, M. Quinton, F. Miglior, K. Thompson, and B. A. Mallard. 2008. Differential gene expression of high and low immune responder Canadian Holstein dairy cows. Dev. Biol. (Basel) 132:315-320.

O'Callaghan, K. A., P. J. Cripps, D. Y. Downham, and R. D. Murray. 2003. Subjective and objective assessment of pain and discomfort due to lameness in dairy cattle. Anim. Welf. 12:605-610.

Raymond, C., B. Wilkie, B. Mallard, and M. Quinton. 1998. Natural killer cell frequency and function in Yorkshire pigs selectively bred for high or low antibody and cell-mediated immune response. Nat. Immun. 16:127-136.

Solano, L., H. W. Barkema, S. Mason, E. A. Pajor, S. J. LeBlanc, and K. Orsel. 2016. Prevalence and distribution of foot lesions in dairy cattle in Alberta, Canada. J. Dairy Sci. 99:6828-6841.

Solano, L., H. W. Barkema, E. A. Pajor, S. Mason, S. J. LeBlanc, J. C. Zaffino Heyerhoff, C. G. R. Nash, D. B. Haley, E. Vasseur, D. Pellerin, J. Rushen, A. M. de Passille, and K. Orsel. 2015. Prevalence of lameness and associated risk factors in Canadian HolsteinFriesian cows housed in freestall barns. J. Dairy Sci. 98:6978-6991.
Stear, M., B. A. Mallard, D. Groth, K. Fairlie-Clarke, and N. Jonsson. 2016. Genetic variation in immunity and disease resistance in livestock. Pages 1-41 in Achieving Sustainable Production of Cow's Milk. Burleigh Dodds Science Publishing, Cambridge, UK.

Stear, M. J., S. C. Bishop, B. A. Mallard, and H. Raadsma. 2001. The sustainability, feasibility and desirability of breeding livestock for disease resistance. Res. Vet. Sci. 71:1-7.

Thompson-Crispi, K. A., B. Hine, M. Quintion, F. Miglior, and B. A. Mallard. 2012b. Short communication: Association of disease incidence and adaptive immune response in Holstein dairy cows. J. Dairy Sci. 95:3888-3893.

Thompson-Crispi, K. A., F. Miglior, and B. A. Mallard. 2013. Incidence rates of clinical mastitis among Canadian Holsteins classified as high, average or low immune responders. Clin. Vaccine Immunol. 20:106-112.

Thompson-Crispi, K. A., A. Sewalem, F. Miglior, and B. A. Mallard. 2012a. Genetic parameters of adaptive immune response traits in Canadian Holsteins. J. Dairy Sci. 95:401-409.

Wagter, L. C., B. A. Mallard, B. N. Wilkie, K. E. Leslie, P. J. Boettcher, and J. C. Dekkers. 2000. A quantitative approach to classifying Holstein cows based on antibody responsiveness and its relationship to peripartum mastitis occurrence. J. Dairy Sci. 83:488-498.

Wikenheiser, D. J., and J. S. Stumhofer. 2016. ICOS co-stimulation: Friend or foe? Front. Immunol. 7:304. https://doi.org/10.3389/ fimmu.2016.00304.

Yano, T., K. K. Moe, K. Yamazaki, T. Ooka, T. Hayashi, and N. Misawa. 2010. Identification of candidate pathogens of papillomatous digital dermatitis in dairy cattle from quantitative 16S rRNA clonal analysis. Vet. Microbiol. 143:352-362. 